\title{
Identifying genetic risk factors for serious adverse drug reactions: current progress and challenges
}

\author{
Russell A. Wilke*, Debbie W. Lin ${ }^{*}$, Dan M. Roden, Paul B. Watkins, David Flockhart, Issam \\ Zineh, Kathleen M. Giacomini ${ }^{\star}$, and Ronald M. Krauss ${ }^{\star}, \neq$ \\ Department of Genome Sciences, Lawrence Berkeley National Laboratory, Berkeley, California \\ 94720; Department of Nutritional Sciences, University of California, Berkeley, California 94720, \\ USA.
}

\begin{abstract}
Serious adverse drug reactions (SADRs) are a major cause of morbidity and mortality worldwide. Some SADRs may be predictable, based upon a drug's pharmacodynamic and pharmacokinetic properties. Many, however, appear to be idiosyncratic. Genetic factors may underlie susceptibility to SADRs and the identification of predisposing genotypes may improve patient management through the prospective selection of appropriate candidates. Here we discuss three specific SADRs with an emphasis on genetic risk factors. These SADRs, selected based on wide-sweeping clinical interest, are drug-induced liver injury, statin-induced myotoxicity and drug-induced long QT and torsades de pointes. Key challenges for the discovery of predictive risk alleles for these SADRs are also considered.
\end{abstract}

\begin{abstract}
Adverse drug reactions (ADRs) are often classified as Type A and Type B. Type A reactions represent an extension of the drug's therapeutic effect; they occur relatively frequently, and they are typically dose-related. Examples include hypotension with anti-hypertensive therapy and bleeding episodes with warfarin. By contrast, Type B reactions are unpredictable, occurring only in susceptible individuals ${ }^{1}$; they are often termed 'idiosyncratic', reflecting our
\end{abstract}

\author{
(C) 2007 Nature Publishing Group \\ Correspondence to R.M.K. rkrauss@chori.org. \\ *These authors contributed equally to this work. \\ ‡Children's Hospital Oakland Research Institute, 5700 Martin Luther King Jr. Way, Oakland, California 94609 \\ Author addresses \\ Russell A. Wilke is at the Department of Medicine and Department of Pharmacology and Toxicology, Medical College of Wisconsin, \\ 8701 Watertown Plank Road, Milwaukee, Wisconsin 53226, USA. \\ Debbie W. Lin and Kathleen M. Giacomini are at the Department of Biopharmaceutical Sciences, GD584 Rock Hall, 1550 4th Street, \\ University of California, San Francisco, California 94143 USA. \\ Dan M. Roden is at Vanderbilt University School of Medicine, 2215B Garland Avenue, Nashville, Tennessee 37232-0575, USA. \\ Paul B. Watkins is at the Department of Medicine, General Clinical Research Center 3005 APCF, 101 Manning Drive, University of \\ North Carolina Chapel Hill, North Carolina 27599, USA. \\ David Flockhart is at the Division of Clinical Pharmacology, Wishard Memorial Hospital Indiana, 1001 West $10^{\text {th }}$ Street, Indiana \\ University School of Medicine, Indiana 46202, USA. \\ Issam Zineh is at the Departments of Pharmacy Practice and Pharmaceutics, College of Pharmacy; Division of Cardiovascular Medicine, \\ College of Medicine; and Center for Pharmacogenomics, University of Florida, Gainesville, Florida 32610, USA. \\ Competing interests statement \\ The authors declare competing financial interest: see web version for details. \\ DATABASES \\ Entrez Gene: http://www.ncbi.nlm.nih.gov/entrez/query.fcgi?db=gene $\underline{A N K 2}|\underline{C A V 3}| \underline{K C N E 1}|\underline{K C N E 2}| \underline{K C N H 2}|\underline{K C N Q 1}|$

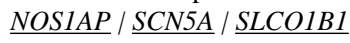 \\ FURTHER INFORMATION \\ Ronald Krauss's homepage: http://www.chori.org/Principal_Investigators/Krauss_Ronald/krauss_overview.html \\ ALL LINKS ARE ACTIVE IN THE ONLINE PDF
}


lack of understanding of their underlying mechanisms. ADRs are referred to as serious adverse drug reactions (SADRs) if they can be generally characterized as requiring hospitalization, prolonging hospitalization, being permanently disabling or fatal ${ }^{2}$. SADRs can arise through either Type A or B mechanisms.

The overall incidence of SADRs in hospitalized patients in the United States has been estimated at $6.2-6.7 \%$ and the incidence of fatal ADRs is estimated to be $0.15-0.3 \%$ (REF. ${ }^{2}$ ). This results in over 2 million estimated SADRs among hospitalized patients annually, with more than 100,000 deaths, making these reactions a significant cause of death in the United States. Studies in Europe and Australia have yielded similar estimates ${ }^{3}$. The resulting cost burden is enormous, representing tens of billions of dollars, and has an impact on both the healthcare and the pharmaceutical industry internationally ${ }^{4}$.

\section{Genomic approaches to SADRs}

Identifying genetic risk factors for SADRs, particularly Type B reactions, could significantly decrease the healthcare costs and improve the process of drug development ${ }^{5}$. Characteristics of SADRs that increase the likelihood of informative genetic (or genomic) analysis include: evidence for a familial or genetic component; accepted criteria for unambiguous diagnosis; objective (for example, laboratory-based) diagnostic data; low background incidence; and availability of sufficient numbers of cases and appropriately matched controls ${ }^{6}$.

Accrual of large numbers of cases will be necessary for the efficient study of genetic factors underlying SADRs. The world's growing biobanks represent a potential resource for studies identifying genetic and other determinants of both rare and common SADRs. Each of these data repositories contains variable amounts of clinical information and biological tissue, reflecting their unique design (for example, disease-based, treatment-based and/or populationbased). In particular, population-based biobanks may prove useful for testing the generalizability of findings in diverse population subgroups (in which background genetic variation and environmental factors, such as differences in concomitant drug use and diet, may affect the results).

\section{Adverse drug reaction}

(ADR). Any noxious, unintended and undesired effect of a drug, which occurs at doses used in humans for prophylaxis, diagnosis or therapy. This excludes therapeutic failures, intentional and accidental poisoning and drug abuse.

As discussed elsewhere ${ }^{5}$, for less common SADRs, such studies may require national or international consortia involving governmental agencies, healthcare systems, and pharmaceutical companies as well as academic medical centres. Control subjects for such studies should be matched for drug exposure, concomitant use of other agents that could affect the pharmacokinetics or pharmacodynamics of the drug in question, gender and ethnicity. It follows that large databases that contain accurate medication data are critical to this effort.

Other desirable features for genetic analysis of SADRs include: information regarding the molecular mechanisms of drug action and pathways for metabolism and elimination that can inform selection of candidate genes for testing genetic polymorphisms; and appropriate cellular and animal models, or in-silico simulations, for testing the functional effects of candidate genotypes. BOX 1 highlights the key criteria needed for genetic analysis of SADRs.

One historical example of a gene-linked ADR is the association of glucose-6-phosphate dehydrogenase (G6PD) polymorphisms with haemolytic anaemia. Severe haemolytic anaemia 
can occur in G6PD-deficient patients after the ingestion of fava beans and after the use of certain anti-malarial drugs or sulphonamides ${ }^{7}$. Worldwide, more than 200 million people are affected by G6PD deficiency, making drug-induced haemolysis a significant concern, particularly in regions endemic for malaria ${ }^{8}$. Other examples include severe prolonged muscle relaxation with suxamethonium in patients with cholinesterase deficiency ${ }^{9}$ and haematologic toxicities in thiopurine-S-methyltransferase-deficient paediatric patients treated with the antineoplastic agent 6-mercaptopurine ${ }^{10}$. One common mechanism underlying SADRs is unusual drug accumulation due to polymorphisms in drug-metabolizing enzymes (or solute transporters); a second mechanism is variation in drug action due to changes in drug target genes $^{1}$.

Between 1976 and 2007, 28 drugs were withdrawn from the US market for safety reasons ${ }^{11-}$ 13 (FIG. 1), thus drug safety remains a top priority of regulatory agencies. In response to growing concerns regarding SADRs, the US Food and Drug Administration (FDA), is developing a plan to modernize the drug-safety system and enhance post-approval safety activities $^{14}$. SADRs that occur before marketing often result in the termination of drug development, whereas those that are identified only after FDA approval are in widespread clinical use. BOX 2 illustrates the drugs that have been found to be associated with genetic risk factors and have undergone FDA labelling changes. Thus, SADRs pose challenges both to patient care and to pharmaceutical development. The types of toxicities that have been associated with drugs withdrawn from the US market between 1976 and 2007 are summarized in FIG. 1.

The cost of bringing a single new drug to market is now estimated to exceed $\$ 800$ million $^{15}$. Most of this expense is incurred in the clinical trials that are required to demonstrate that the drug is safe and effective. Reducing the size and length of drug trials is therefore a high priority for the pharmaceutical industry. From the efficacy standpoint, there are several emerging strategies that should make it possible to reduce the size of many clinical trials, including the use of knowledge regarding the genetic heterogeneity of disease in order to target individuals that are most likely to benefit from new treatments. By contrast, there are currently no viable strategies to reduce the number of patients required in a clinical trial to demonstrate drug safety. Safety considerations can therefore dictate the high costs of drug development, at least until there is an improved understanding of the mechanisms underlying SADRs ${ }^{5}$.

In principle, the identification of genetic risk factors for SADRs could lead to the safer use of drugs. Patient-related risk factors for a given SADR may include both genetic and non-genetic risk factors. Historically, it has been difficult to discern the genetic components underlying any particular SADR; however, new genetic and genomic approaches may facilitate the identification of biological risk markers and reveal novel underlying mechanisms.

At present, converging lines of evidence point to genetic factors in the pathogenesis of many predictable ADRs, and basing drug choice and/or dose on a patient's genetic make-up seems likely to result in improved drug efficacy and safety. Of 27 drugs that are frequently cited in ADR studies, $59 \%$ are metabolized by at least one enzyme with a variant allele known to be associated with decreased drug metabolism ${ }^{16}$. Examples of other mechanisms predisposing patients to the development of a clinically relevant ADR include abacavir hypersensitivity ${ }^{17}$ and carbamazepine-induced severe cutaneous ADRs ${ }^{18}$. Here, we review current knowledge of three major drug-induced toxicities: liver injury, myotoxicity and torsades de pointes, and focus on the identification of genetic risk factors that are associated with their occurrence. 


\section{Drug-induced liver injury}

\section{Description and significance}

Drug-induced liver injury (DILI) is a major reason for regulatory actions against marketing approval, removal from the market place and restriction of prescribing indications ${ }^{19}$.

\section{Pharmacokinetics}

The study of processes impacting absorption, distribution, metabolism and excretion of a drug and its metabolites in the body.

\section{Pharmacodynamics}

The study of the mechanism of action of a drug, including but not limited to processes such as receptor binding and signal transduction.

Most drugs responsible for severe DILI are not predictable hepatotoxins. Rather, they are completely safe over a wide range of doses for the vast majority of treated patients, but severely toxic to a small subset of patients ${ }^{20}$. The onset of liver injury is characteristically delayed weeks or months after starting therapy, and the liver injury is generally diffuse ${ }^{19}$. In most instances, it is unclear what makes some individuals susceptible to liver toxicity, but available data support a substantial genetic contribution. TABLE 1 summarizes some of the studies that have reported statistically significant associations between specific gene polymorphisms and susceptibility to DILI. These risk factors involve polymorphisms in two major categories of genes: the highly polymorphic genes in the major histocompatibility locus on chromosome 6 , which encode antigen-presenting proteins; and various polymorphic genes that encode drug metabolizing enzymes. Because the populations in these studies have generally been small, only common polymorphisms have been tested as susceptibility alleles for DILI.

In a prospective study, idiosyncratic DILI accounted for $11 \%$ of all patients with acute liver failure ${ }^{21}$. This would suggest that there are only about 200 cases of acute liver failure due to idiosyncratic DILI per year in the US, assuming roughly 2,000 cases of acute liver failure occur annually ${ }^{22}$. On the other hand, asymptomatic elevations in liver chemistries, particularly of serum alanine aminotransferase (ALT), are commonly caused by drugs ${ }^{23}$. However, even large elevations in serum ALT do not necessarily indicate clinically important liver injury. This is because most patients with ALT elevations that are associated with DILI appear to adapt to the event ${ }^{19}$. Such patients have spontaneous resolutions of the ALT elevations despite continuing treatment. For example, 2 out of 100 patients treated with troglitazone - a peroxisome proliferator-activated receptor agonist for type II diabetes - developed ALT elevations that were three times over the upper limits of normal (ULN), but less than 1 in 1,000 patients developed symptomatic liver injury in an unmonitored situation ${ }^{24}$. Hence, patients with ALT elevations, even large ones, will not necessarily have the most clinically important determinants of severe idiosyncratic reactions (that is, the susceptibility factors for irreversible injury).

In contrast to serum ALT elevations, the presence of jaundice due to a drug generally indicates clinically important liver injury. It has been noted that there is approximately $10 \%$ mortality among patients who seek a physician after they become jaundiced due to hepatocellular injury (that is, hepatocellular jaundice) $)^{25}$.

\section{Box 1 | Criteria for informative pharmacogenetic SADR studies}

\section{Definition of serious adverse drug reaction (SADR) phenotype}

Characteristics of SADRs that increase the likelihood of informative genetic/genomic analysis include: 
- Evidence for a familial or genetic component.

- Accepted criteria for unambiguous diagnosis.

- Low background incidence.

- Availability of sufficient numbers of cases and appropriately matched controls.

Other desirable features include:

- Information regarding the molecular mechanisms of drug action that can inform selection of candidate genes and pathways for testing genetic polymorphisms.

- Appropriate cellular and animal models, or in-silico simulations, for testing functional effects of candidate genotypes.

\section{Availability of adequate numbers of cases}

Accrual of large numbers of cases is mandatory for understanding the genetic and other determinants in both rare and common adverse reactions to drugs. Potential resources to enable such accrual include the Food and Drug Administration Adverse Events Reporting System (AERS) database of spontaneous case reports. Other key resources include large National Institutes of Health (NIH) and industry-sponsored clinical trials. Databases from healthcare systems may prove useful if the data are primarily electronic and if they contain medication data in a coded format, or a format that can be efficiently validated.

\section{Selection of appropriate controls}

Key elements are matching for drug exposure (that is, dose and duration), clinical covariates (that is, age, gender, race and ethnicity) and the concomitant use of other agents that could interact with the drug in question (that is, through either pharmacokinetic or pharmacodynamic mechanisms).

Based on the above observations, it seems likely that potentially life-threatening idiosyncratic DILI will ultimately reflect the presence of at least two distinct sets of susceptibility factors in the host. The first set of factors involves a predisposition to low-level injury, typically reflected in ALT elevations. For drugs where toxicity is believed to result from a toxic metabolite produced in the liver, this first set of factors can include genetic variation in drug metabolizing and detoxifying enzymes or drug transporters, and may be relatively drug specific (see TABLE 1 for examples). The prevailing hypothesis is that this initial liver injury will be transient despite continued treatment with the drug, unless the patient has a second, probably unrelated, predisposition, which prevents adaptation and/or accelerates the initial injury. There are few clues as to the nature of these secondary factors, although some evidence suggests that the innate immune system and protective mechanisms present in the liver may be involved ${ }^{26}$. These secondary factors might be much less molecule specific, such as the association of G6PD deficiency with haemolytic anaemia, which is induced by numerous drugs ${ }^{7}$. It has not been possible to test hypotheses about these secondary factors because there has never been a systematic collection of genomic DNA from patients with severe DILI. The few genomic DNA collections to date have been from patients with generally mild DILI, such as ALT elevations in clinical trials.

Prospective studies of DILI, whether performed in an academic or industrial setting, are unlikely to be able to distinguish patients with this second set of predisposing factors from among those with the first set alone. This is because the implicated drug will usually be stopped when ALT elevations are detected and before jaundice would appear. These considerations led the National Institute of Diabetes and Digestive and Kidney Diseases of the National Institutes of Health to sponsor a cooperative agreement to create a Drug-Induced liver Injury Network 
(DILIN) ${ }^{27}$. The goal of DILIN is to determine causation and enrol referred cases into ongoing clinical studies. One approach is summarized below.

\section{Criteria for diagnosis of DILI}

Among the SADRs, DILI is one of the more difficult ones to confidently diagnose. There are no blood tests to confidently establish causality and liver biopsies are rarely conclusive. Several diagnostic instruments such as the Roussel Uclaf Causality Assessment method (RUCAM) and the Maria \& Victorino $(\mathrm{M} \& \mathrm{~V})$ clinical scale have been proposed ${ }^{28}$, but clear diagnosis of DILI includes multiple factors and should be made by a clinician with expertise in hepatology or gastroenterology. The key to making the correct diagnosis is exclusion of other potential causes of liver injury, which generally requires complete case data, including records of all clinical laboratory and radiologic results, and a full medical history to allow the evaluation of alternative causes. Hence, it becomes necessary to obtain the original source documentation for all patients. Interview with the patient and study-related physical examination, although desirable, is generally not necessary if the documentation is complete. Even with complete information, it is usually not possible to make a diagnosis of DILI with $100 \%$ certainty because severe and even fatal liver injury occurs when no aetiology is evident; approximately $15 \%$ of patients with acute liver failure are in this 'idiopathic' category ${ }^{21}$. If such a patient recently started a new medication, the role of this medication needs to be evaluated, as the medication may have been causative or it might be erroneously implicated. It is therefore important that the number of prior reports of liver injury that are associated with the suspect medication are considered. In general, idiopathic liver failure occurs in approximately 1 in 1 million adults a year in the United States ${ }^{26}$. As a subset of these cases are likely to be attributable to a hepatotoxic process set in motion by a drug, the potential for genetic risk markers to reduce the overall frequency of unexplained liver failure is likely to be quite substantial.

\section{Statin-induced muscle toxicity}

\section{Description and significance}

Multiple, large clinical trials have demonstrated that statins (3-hydroxy-3-methylglutaryl coenzyme A (HMG CoA) reductase inhibitors) reduce the incidence of both primary and secondary coronary artery disease in patients at risk ${ }^{29-31}$. Each of the six currently available statin drugs is regarded as both safe and efficacious. Over the past several decades, experience with this class of drugs has expanded into millions of patients. As a result, statin-related muscle complications are becoming better characterized ${ }^{32-34}$. In general, the frequency of statinrelated muscle complications depends on how the ADR is defined clinically. Statin-induced muscle complications appear to be dose-dependent ${ }^{34}$, and they have been described diagnostically as myalgia (focal or diffuse muscle pain), myopathy (pain in the absence of inflammation), myositis (pain accompanied by a systemic inflammatory response) and rhabdomyolysis (severe muscle damage accompanied by damage in another organ, most notably the kidneys) ${ }^{33,34}$.

\section{Box 2 | FDA labelling changes in drugs associated with genetic risk factors}

\section{6-Mercaptopurine}

\section{Gene TPMT}

Individuals who are homozygous for an inherited defect in the TPMT (thiopurine $S$ methyltransferase) gene are unusually sensitive to the myelosuppressive effects of mercaptopurine and prone to developing rapid bone-marrow suppression following the initiation of treatment. Laboratory tests are available, both genotypic and phenotypic, to determine TPMT status. Substantial dose reductions are generally required for homozygous-TPMT deficiency patients (with two non-functional alleles) to avoid the 
development of life-threatening bone marrow suppression. Although heterozygous patients with intermediate TPMT activity may have increased mercaptopurine toxicity, this is variable, and most patients tolerate normal doses of drug. If a patient has clinical or laboratory evidence of severe toxicity, particularly myelosuppression, TPMT testing should be considered. In patients who exhibit excessive myelosuppression due to 6mercaptopurine, it may be possible to adjust the mercaptopurine dose and administer the usual dosage of other myelosuppressive chemotherapy as required for treatment ${ }^{130}$.

\section{Azathioprine}

\section{Gene TPMT}

It is recommended that consideration is given to either genotype or phenotype patients for $T P M T$. Phenotyping and genotyping methods are commercially available. The most common non-functional alleles that are associated with reduced levels of TPMT activity are $T P M T * 2, T P M T * 3 A$ and $T P M T * 3 C$. Patients with two non-functional alleles (homozygous) have low or absent TPMT activity and those with one non-functional allele (heterozygous) have intermediate activity. Accurate phenotyping (red blood cell TPMT activity) results are not possible in patients who have received recent blood transfusions. TPMT testing may also be considered in patients with abnormal complete blood count (CBC) results that do not respond to dose reduction. Early drug discontinuation in these patients is advisable ${ }^{131}$.

\section{Warfarin}

\section{Gene CYP2C9; VKORC1}

The recently revised warfarin product label adds $C Y P 2 C 9$ and $V K O R C 1$ genetic variations to the list of clinical considerations for warfarin use. The label's specific warfarin dose recommendations have not changed. The warfarin label provides information on how people with certain genetic differences in the two genes may need lower warfarin doses than people without these genetic variations. The $C Y P 2 C 9$ gene product is involved in the metabolism of warfarin and the $V K O R C 1$ gene product helps regulate the ability of warfarin to prevent blood from clotting. Patients with $C Y P 2 C 9 * 2$ and $C Y P 2 C 9 * 3$ genetic variations are at an increased risk of bleeding with warfarin therapy ${ }^{132}$.

\section{Irinotecan}

\section{Gene UGT1A1}

Patients with reduced UGT1A1 activity, and those who are homozygous for the $U G T 1 A 1 * 28$ allele, are at increased risk of neutropenia following initiation of irinotecan treatment. A reduced initial dose should be considered for patients who are homozygous for the $U G T 1 A I * 28$ allele. Heterozygotes (carriers of one variant allele and one wild-type allele that results in intermediate UGT1A1 activity) may be at increased risk for neutropenia ${ }^{133}$.

The frequency of clinically significant muscle toxicity remains a matter of ongoing debate ${ }^{33}$ Circulating levels of creatine kinase (CK) are often used clinically as a marker of severity for statin-induced muscle damage ${ }^{33-35}$. However, the presence of statin-induced muscle damage may or may not be accompanied by leakage of muscle enzymes into the blood ${ }^{35-37}$. For most statins, diffuse myalgias (or arthralgias) are reported in the absence of CK elevation in 1-5\% of the subjects exposed ${ }^{32}$. Myalgias with a mild to moderate elevation in circulating CK level (3-10-fold ULN) occur in less than $1 \%$ of $\operatorname{cases}^{34,38}$. For lovastatin and simvastatin in particular, the prevalence of mild CK elevation appears to be approximately 6.4 cases per 1,000 patients ${ }^{38}$. This estimate decreases to 1.6 cases per 1,000 patients if the definition is restricted to only those subjects with a high degree of CK elevation ${ }^{38}$. In general, confirmed myopathy 
(defined clinically as CK levels that are greater than 10-fold ULN) occurs in less than $0.1 \%$ of patients on statin monotherapy ${ }^{34,35,38}$.

In the absence of true myopathy, however, adverse muscle symptoms (or mild CK elevation) can still cause a patient (or their physician) to alter the course of their clinical care. For example, mild but diffuse myalgias will often cause a patient to consider switching to a different drug or discontinue statin therapy altogether. If the patient's laboratory data show a mild-to-moderate elevation in serum CK level, the physician may agree. In these situations, it is helpful if a baseline serum CK level, obtained before the initiation of therapy, is available.

A mild elevation in serum CK levels might represent an adequate phenotype for the resolution of genetic predictors. Recently, an association between a candidate drug metabolizing enzyme gene polymorphism $(C Y P 3 A 5 * 3)$ and the degree of $\mathrm{CK}$ elevation in myotoxicity case subjects exposed to atorvastatin was reported ${ }^{39}$. In this retrospective study ( $\mathrm{n}=68$ cases and 69 controls), case status simply required an elevation in serum CK level greater than ULN (while the subject was on the drug); a compelling pain syndrome was not required for case assignment ${ }^{39}$.

There is precedent for a statin-induced myotoxicity phenotype represented by elevated circulating CK levels in the absence of pain. Draeger and colleagues have documented ultrastructural damage (for example, breakdown of T-tubules and sarcolemmal rupture) in skeletal muscle biopsies obtained from statin-exposed subjects with no myalgias ${ }^{40}$. Although the clinical significance of this latter phenotype (often termed 'asymptomatic myopathy') remains unclear, further studies are warranted to determine whether these subjects are at increased risk for progression to rhabdomyolysis.

\section{Gilbert's syndrome}

A common, mild liver disorder caused by reduced activity of glucuronyltransferase, an enzyme required for excreting bilirubin; typically it does not require treatment or pose serious complications.

\section{Creatine kinase}

(CK). An enzyme often measured clinically as a severity marker of muscle damage.

As noted above, the frequency of rhabdomyolysis is extremely low. A review of the records of more than 250,000 patients treated with atorvastatin, pravastatin or simvastatin, revealed that rhabdomyolysis was reported at an incidence of 0.000044 events per person per year in subjects receiving monotherapy ${ }^{41}$. Others have reported that rosuvastatin is associated with similarly low rates of rhabdomyolysis (at doses less than $40 \mathrm{mg}$ ) ${ }^{42,43}$. Therefore, in the context of a severe statin-induced ADR (that is, rhabdomyolysis), which is known to occur at a very low frequency, it may be difficult to obtain sufficient cases to adequately assess genetic predictors. Case control studies designed to answer such a question will need to screen millions of patients exposed in order to identify and recruit an adequate number of study subjects.

\section{Factors affecting risk}

Despite the dramatic clinical efficacy statins, prescribing them can be complicated due to the differential biochemical properties of each individual drug. Some statins are highly lipophilic whereas others are highly hydrophilic, so the overall kinetic profile for this therapeutic class differs on a drug-by-drug basis ${ }^{44}$. Statin kinetics are further modified by population-based differences in clinical factors, such as age, body size and body composition. The severity of atorvastatin-induced muscle toxicity (defined by CK level only) has been reported to be associated with younger age ${ }^{39}$. It is conceivable that age-related differences in lean body mass (younger people have, proportionally, more lean body mass than older people) could be 
associated with higher serum CK levels as CK is derived through muscle turnover and muscle represents lean body mass. It has been reported that the severity of atorvastatin-induced muscle toxicity was associated with male gender ${ }^{39}$, but it is conceivable that this difference was attributable to participation bias. Conversely, it is also conceivable that this difference was due to gender differences in drug metabolism and elimination. The serum half-life for atorvastatin is known to be $20 \%$ shorter in women than in $\mathrm{men}^{45}$. Because the parent drug is metabolized more rapidly in women, it is plausible that men have a slightly greater exposure for any given dose. This hypothesis requires testing.

The degree to which genetic factors contribute to patient-to-patient variability in statin metabolism is an active area of investigation. Whereas some statins undergo a great deal of phase I metabolism ${ }^{46}$, others appear to undergo very little ${ }^{47}$. Even among the statins that undergo phase I oxidation, the primary enzyme may differ on a drug-by-drug basis.

Atorvastatin is oxidized primarily by members of the cytochrome P450 (CYP) 3A family 48 . Although these enzymes are known to have a role in the metabolism of simvastatin as well, data have also suggested a role for CYP2D6 in the oxidation of simvastatin metabolites ${ }^{49-53}$. Fluvastatin, on the other hand, is metabolized to a great degree by CYP2C9 (REFS ${ }^{54,55}$ ). Each of these enzymes - CYP2C9, CYP2D6 and CYP3A $4 / \underline{5}$ - is genetically polymorphic. Phase I drug metabolizing enzyme gene polymorphisms may therefore account for population differences in myotoxicity risk. Following oxidative phase I drug metabolism, many statins form hydroxyl intermediates (for example, atorvastatin is converted to 2-OH atorvastatin and $4-\mathrm{OH}$ atorvastatin ${ }^{48}$, whereas simvastatin is converted to $3-\mathrm{OH}$ simvastatin and 6-OH simvastatin $^{56}$ ). These hydroxy-statin derivatives are then subjected to additional modification, through phase II metabolism (conjugative enzymes) by UDP-glucuronosyltransferase-1 (UGT1) (REFS ${ }^{53,57}$ ). This process may yield a variety of biologically active lactone derivatives (for example, $2-\mathrm{OH}$ atorvastatin lactone ${ }^{58}$ or simvastatin lactone ${ }^{57}$ ). Gemfibrozil is thought to alter the pharmacokinetics (and corresponding clinical outcomes) of various statin drugs through a UGT1-dependent interaction ${ }^{57}$. By inhibiting the glucuronidation of simvastatin hydroxy acid, gemfibrozil attenuates the biliary excretion of simvastatin and puts patients at increased risk of developing statin-related toxicity. Furthermore, polymorphism in UGTl alters the risk of developing cerivastatin-related muscle complications in patients using other concomitant lipid-lowering agents ${ }^{42,57,59,60}$. Whether similar interactions (at the level of UGT1) will alter other statin-related outcomes is undetermined, but recent data suggest that this is likely ${ }^{39,61}$.

Membrane transporters are also thought to modulate a variety of statin-related clinical outcomes. Polymorphisms in candidate solute transporter genes (for example, organic anion transporters) have been associated with altered hepatic uptake of pravastatin ${ }^{62,63}$, and studies have revealed that gemfibrozil attenuates the uptake of rosuvastatin ${ }^{61}$ and cerivastatin ${ }^{42,60}$ through an interaction with these gene products. There is growing evidence that genetic variation in solute carrier organic anion transporter family, member 1B1 (SLCO1B1), in particular, might have an effect on subject variability in statin-related outcomes ${ }^{4,64}$. As the respective gene products modulate the cellular transport of statins differentially ${ }^{64}$, it is tempting to speculate that $S L C O 1 B 1$ gene polymorphisms might allow us to predict a subject's risk of developing statin-induced myotoxicity on a drug-by-drug basis ${ }^{65}$. This hypothesis is currently being tested.

\section{Phase I metabolism}

Phase I reactions may occur by oxidation, reduction, hydrolysis, cyclization and decyclization reactions. The process of oxidation takes place in the presence of mixed function oxidases and mono-oxygenases in the liver. 


\section{Phase II metabolism}

Phase II reactions (conjugation reactions) are usually detoxicating and involve the interactions of the polar functional groups of phase I metabolites.

TABLE 2 summarizes a number of polymorphisms already associated with statin-induced mytotoxicity. Much of this work has been conducted within the framework of studying candidate genes. Genetic variability in phase I (oxidative) drug metabolizing enzymes may predispose subjects to a more severe form of myotoxicity in the context of statin therapy 39 , 66. However, not all statins undergo phase I oxidation. Any model of genetic variability in statin disposition must therefore also include phase II metabolism and cellular processes known to affect drug transport ${ }^{65}$. To date, a subject's risk of developing statin-induced myotoxicity has been associated with genetic variability in at least three membrane transporters ${ }^{66-68}$. As gene expression studies provide additional molecular insight into the mechanisms underlying this SADR, interesting toxicodynamic candidate genes are also emerging ${ }^{69,70}$.

\section{Criteria for identifying statin-induced rhabdomyolysis}

Clinically, the most important SADR associated with statin therapy is rhabdomyolysis ${ }^{41}$. The clinical definition of rhabdomyolysis has recently been reviewed ${ }^{33-35}$. The Advisory Panel for the National Cholesterol Education Program (NCEP) defines rhabdomyolysis as a CK level greater than 10-fold ULN with renal compromise, whereas the US FDA requires a CK level greater than 50-fold ULN with organ damage ${ }^{30}$. A 50 -fold elevation in serum CK level typically equates to a circulating CK level of approximately 10,000 International Units (IU) per litre. Phenotyping strategies for research purposes may differ. One strategy that uses both outpatient and inpatient data for myotoxicity case finding is illustrated in FIG. 2. In an alternative hospitalbased strategy, Graham et al. have specifically identified cases of rhabdomylosis in statintreated patients using the following three categories ${ }^{41}$ : Hospital discharge diagnoses possibly indicative of severe muscle injury (combined with ancillary laboratory data such as urine myoglobin levels); evidence from medical records for severe muscle injury at the time of hospital admission with an admitting diagnosis of rhabdomyolysis; and CK levels above 10fold ULN (severe rhabdomyolysis was defined as CK levels above 50-fold ULN — that is, CK greater than 10,000 IU per L).

Using the latter (most stringent) definition for the construction of genetic association studies, sufficient numbers of drug-induced rhabdomyolysis cases may be difficult to recruit. For research purposes, one alternative approach might be to identify genetic determinants of risk specifically associated with either mild to moderate CK elevation (3-10-fold ULN) or myopathy (greater than 10-fold ULN). At an estimated frequency of $0.1 \%$ (REFS $29,30,32$ ), investigators can expect to identify up to 10,000 potential myopathy case subjects for every 10 million patients exposed to statins. The implementation of such an effort will likely require the establishment of a coordinated multi-institutional study team, possibly at the global level ${ }^{5}$.

\section{Drug-induced long QT syndrome}

\section{Description and significance}

The morphologically distinctive ventricular tachycardia termed 'torsades de pointes' occurs in $1-5 \%$ of patients treated with anti-arrhythmic agents that are known to have QT prolonging properties $^{71-75}$. When this occurs, there is also prolongation of the QT interval on the surface electrocardiogram (ECG), often most evident on the beat(s) just before the onset of the arrhythmia $^{71,76,77}$; and basic scientific studies have implicated abnormal cardiac repolarization - represented as the QT interval on the surface ECG - as an integral mechanistic feature of

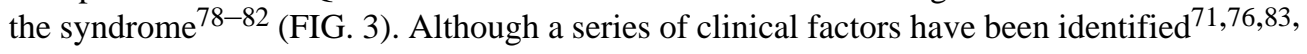


84 , the reaction in an individual patient remains unpredictable. The basic electrophysiological mechanisms in this syndrome have been established and provide a series of candidate genes for initiating genomic analysis of risk, as discussed below.

This abnormal electrophysiological response to drug challenge can also occur, albeit much less commonly, with non-cardiovascular drugs ${ }^{77,85}$. Despite its rarity, this SADR can be sufficiently alarming to upset the balance between risk and benefit that goes into approval or prescription of any drug. Indeed, the drug-induced long QT syndrome (LQTS) leading to fatal arrhythmias has been one of the most common causes for drug withdrawal from the marketplace in the last decade (FIG. 1), and pre-clinical and pre-marketing evaluation of QT prolonging potential of new drug candidates now represents a major effort in the pharmaceutical industry ${ }^{85-87}$.

\section{Hypokalaemia}

Hypokalaemia is a potentially fatal condition in which the body fails to retain sufficient potassium to maintain health. The condition is also known as potassium deficiency.

\section{Factors affecting risk}

Multiple clinical risk markers of torsades de pointes, notably hypokalaemia, hypomagnesaemia, underlying bradycardia, coexistent heart disease and female gender, have been identified and will need to be considered in the analysis of any comprehensive genotypephenotype association study ${ }^{71,76,84,88-90}$. Familial syndromes characterized by an association between abnormal cardiac repolarization, manifest as marked prolongation of the QT interval on the surface ECG, and a high risk for sudden cardiac death (SCD) were first described in the 1950s and 1960s (REFS ${ }^{91-93}$ ), and ten disease genes for the congenital LQTS have been identified since 1995 (REFS ${ }^{94-104}$ ). The two most commonly affected genes ( $K C N Q 1$, originally known as $K v L Q T 1$, and $K C N H 2(H E R G)$ ) encode the voltage-gated potassium channels underlying the currents $\mathrm{I}_{\mathrm{Ks}}$ and $\mathrm{I}_{\mathrm{Kr}}$, respectively. Six of these ten disease genes also encode ion channel proteins or ancillary (function-modifying) subunits, and the remaining two disease genes, $\underline{A N K 2}$ and $\underline{C A V 3}$, do not encode ion channels but are thought to modify channel function. The ankyrin-B protein encoded by $A N K 2$ appears to target calcium-handling proteins to appropriate membrane subdomains within myocytes ${ }^{97}$, whereas the $C A V 3$ gene encodes a caveolar protein that appears to modify sodium channel function ${ }^{101}$.

Each disease-associated mutation above upsets the balance between inward depolarizing and outward repolarizing currents during cardiac repolarization in favour of increased net inward current, resulting in prolonged action potentials and hence, increased QT intervals on the surface ECG. Virtually all drugs that cause torsades de pointes block $\mathrm{I}_{\mathrm{Kr}}$ /human ether-a-gogo-related (HERG) channels ${ }^{85,88-90,105,106}$, supporting a link between the familial and drugassociated forms of the syndrome. This action potential prolongation is thought to be especially exaggerated in mid-myocardial (M cells) and Purkinje cells compared with those in epicardial and endocardial cells; the resulting increased heterogeneity in action-potential durations is then postulated to create the substrate for reentrant excitation that generates torsades de pointes ${ }^{88}$, 107. The role of $\mathrm{M}$ cells and of transmural heterogeneity has received considerable attention as a mediator of this (and other) arrhythmias, but this construct is not universally accepted ${ }^{108}$, ${ }^{109}$. Early after-depolarizations in M or Purkinje cells, which are generated by inward currents, such as $\mathrm{I}_{\mathrm{Na}}, \mathrm{I}_{\mathrm{Ca}-\mathrm{L}}$ or $\mathrm{I}_{\mathrm{ti}}$, may serve as triggers to initiate this re-entry ${ }^{107,110}$.

Disease genes identified in congenital LQTS are high priority candidates for the drug-induced form of the syndrome. In addition, they implicate other genes that are directly or indirectly involved in the control of cardiac electrical signalling. One important finding that has emerged 
as families with the congenital LQTS are studied is variable penetrance of the clinical phenotype $^{111}$. One way in which this feature of the disease may become manifest is the development of marked QT prolongation and arrhythmias following drug exposure of subclinical mutation carriers to QT-prolonging drugs ${ }^{112-114}$. TABLE 3 emphasizes that although HERG inhibition is the mechanism underlying QT prolongation by drugs, variants in other channels can exaggerate this effect, consistent with the concept of 'reduced repolarization reserve' discussed below. Furthermore, in a screen of the coding regions of 5 congenital LQTS disease genes $(K C N Q 1, \underline{K C N H 2}, \underline{K C N E 1}, \underline{K C N E 2}$ and $\underline{S C N 5 A})$ in $\sim 90$ patients with drug-induced torsades de pointes, mutations compatible with the subclinical congenital syndrome were found in $\sim 5 \%$ of them ${ }^{114,115}$. An ANK2 screen in ethnic controls (165 patients with exaggerated drug-induced QT prolongation, most of whom also had torsades, and 280 patients with other congenital arrhythmia syndromes) identified 8 ANK2 nonsynonymous cSNPs in 14 out of $635(2.2 \%)$ subjects ${ }^{116}$. Three were found in more than one subject, and further in vitro studies demonstrated a range of functional defects that roughly correlated with the severity of the clinical presentations.

In addition, polymorphisms in the LQTS disease genes have also been implicated as increasing risk: D85N $(K C N E 1)^{117}, \mathrm{~S} 1103 \mathrm{Y}(S C N 5 A)^{118,119}$, T8A $(\text { KCNE2 })^{115}$ and Q9E $(K C N E 2)^{94}$. Q9E was originally identified as a mutation based on its absence from over 1,000 normal individuals; however, this variant is now recognized as a relatively common polymorphism in African-Americans. Two candidate gene analyses (148 and 174 SNPs) have suggested that variants in $H E R G$ and in $K C N Q 1$ can modulate the normal QT interval and drug-induced LQTS $^{120}$. Most recently, a genome-wide analysis identified variants in NOSIAP (also known as $C A P O N$ ), a putative subunit of neuronal nitric oxide synthase, as a modulator of the normal QT interval ${ }^{121}$, and thus by extension as a candidate for mediating drug-induced lQTS risk.

\section{Penetrance}

The frequency, under given environmental conditions, with which a specific phenotype results from a predetermined genotype; it is usually given as a percentage.

\section{Subclinical mutation carrier}

A carrier of a mutation who does not manifest the pathological effects of the mutation.

The vast majority of heartbeats in patients with congenital LQTS arise from normal sinus rhythm mechanisms and in many instances are even accompanied by normal QT intervals. Similarly, although $\mathrm{I}_{\mathrm{Kr}}$ block is now recognized as the major initiating mechanism in druginduced torsades de pointes, not every patient receiving culprit drugs develops marked QT prolongation or arrhythmia. Indeed, the frequency of mutation carriers for the congenital syndrome is now estimated at 1 in 1,000 to 1 in 3,000, yet the frequency of torsades for many non-cardiovascular drugs (such as terfenadine or cisapride) is much lower, indicating that even exposure to a patient with the congenital syndrome may not elicit arrhythmia. This lack of a simple relationship between reduced $\mathrm{I}_{\mathrm{Kr}}$ and a manifest clinical phenotype indicates that risk can be modulated by a factor(s) beyond $\mathrm{I}_{\mathrm{Kr}}$ block alone. Variable drug metabolism can be invoked in some cases of drug-associated torsades de pointes ${ }^{122}$ but this is far from a universal explanation, and will not explain variability in the congenital syndrome. The concept of 'repolarization reserve' ${ }^{\prime 23}$ has been developed to explain this variability in response to a reduction or block of $\mathrm{I}_{\mathrm{Kr}}$; the notion is that as multiple mechanisms contribute to normal repolarization, loss of function in one of these (for example, reduced $\mathrm{I}_{\mathrm{Kr}}$ ) might not lead to clinical consequences unless other lesions are present. Examples of such lesions are subclinical mutations in ion channel or other genes, or disordered electrogenesis, which is increasingly recognized in acquired diseases such as heart failure or left ventricular hypertrophy ${ }^{123}$. The physiological concept corresponds to thinking in contemporary genomics postulating gene- 
gene or gene-environment interactions as crucial modulators of clinical phenotypes, and may be equally applicable to other instances of rare genetically mediated drug-induced syndromes. Indeed, recent studies provide support for the idea that $\mathrm{I}_{\mathrm{Ks}}$ might be one important source of repolarization reserve that protects against torsades de points during $\mathrm{I}_{\mathrm{Kr}}$ block ${ }^{124,125}$.

\section{Criteria for identifying long QT and torsades de pointes}

Diagnosis of LQTS and torsades de pointes is based exclusively on the interpretation of the surface ECG. Thus, it is critical in ascertaining cases that clear ECGs are documented in patients and control populations. Corrected QT intervals of greater than 500-520 msec are generally considered indicative of LQTS. Torsades de pointes has a characteristic pattern on ECG, which is usually preceded by a stereotypical series of cycle length changes. Diagnosis of torsades is best made by clinicians with expertise in cardiology. Through well-designed pharmacogenetic association studies, the identification of genomic predictors of drug-induced QT prolongation has the potential to inform the safer use of existing medications and support the development of novel medications in the future. Such studies are also likely to lead to the identification of new genes that modulate cardiovascular disease in general.

\section{Challenges in SADR pharmacogenetics}

Population-based, post-approval monitoring for SADRs clearly represents a critical element of the overall risk management paradigm ${ }^{126}$. As evidenced from the above examples, pharmacogenetic evaluation of SADRs will require the interrogation of large patient databases containing well-characterized cases and carefully selected controls. A common feature among the three examples discussed above is the evidence that the extreme (versus intermediate) SADR phenotype may require the convergence of multiple risk factors, possibly involving distinct pathways; this might contribute to the rarity and the unpredictability of these reactions.

Partnerships or networks of scientists in healthcare systems, academia, regulatory agencies and industry are needed. Non-uniform or non-standardized definitions of clinical phenotypes for SADRs are a major challenge in identifying genetic risk factors. Clearly phenotypes need standardization so that partnerships can be formed to ascertain cases and controls, and to facilitate replication studies. Such standardization will require leadership and groups of scientists, clinicians and regulators must participate in such a process. Improved recording of medication data, including drug dose and use of other medications, in large epidemiologic studies and in records linked to biobanks is also critical. A related issue, given that phamacokinetic mechanisms are of crucial importance for many SADRs, is to consider the extent to which results from different drugs in the same class can be pooled.

\section{Pharmacogenetics}

The study of how variations in a few genes affect the response to medications.

Effective procedures for enlisting the participation of physicians and patients in research protocols, including the collection and transfer of clinical information, DNA, plasma and/or other tissue specimens must be developed. Confidentiality and ethical issues must be considered in the design and implementation of clinical studies aiming to archive DNA and tissue.

Project-specific logistics regarding the approval to conduct research is a pivotal consideration. Careful attention to institutional review board approval for individual projects is essential, with the appropriate stipulations regarding protection of human subjects and privacy. Although we have partly addressed these issues, it is likely that the complexity of implementing such projects will increase with the growing number of study sites and questions. 
Although beyond the scope of this Review, statistical and methodological issues regarding genetic association studies must also be explicitly and continually addressed, allowing flexibility and revised approaches during the process of data gathering and analyses ${ }^{127,128}$. Recent studies have suggested that new candidate mechanisms for various common diseases may be discovered with genome-wide association studies ${ }^{129}$. However, such studies require a large number of samples, especially if the effect sizes of individual SNPs are small. Sample size remains a key challenge in studying the genetics of SADRs. Furthermore, current genomewide association studies assume that common variants will associate with common diseases. Because of rarity, some SADRs do not conform to this assumption. Thus, using genome-wide association analysis to identify less common risk alleles for SADRs will require even larger sample sizes. New technologies for rapid sequencing will help in the identification of less common variants. Candidate gene studies can be performed with fewer samples; however, candidate gene studies require some knowledge of mechanism, which is not available for many cases of SADRs. Investigators must be versed in issues regarding genetic test performance characteristics, epistasis and sources of confounding (for example, population stratification and potential effects of environmental factors, such as diet), and should be able to minimize threats to both internal and external validity as appropriate.

Several regional networks to study SADRs have been established, including a network in Canada, focused on SADRs in children and one in Europe (EUDRAGENE) that is focused on six SADRs in multiple European populations. BOX 3 lists networks that are focused on SADRs with efforts in genetics. These networks together with new networks from other communities could form a global consortium with the goal of standardizing phenotypes and more effectively conducting studies to identify genetic risk factors for SADRs ${ }^{5}$.

\section{Box 3 | Networks with genetics efforts in drug induced toxicity}

\section{Canadian Genotype-specific Approaches to Therapy in Childhood program}

GATC. www.genomecanada.ca/xresearchers/researchPrograms Drugs studied: amoxicillin, carbamazepine, valproic acid, cefprozil, infliximab and isotretinoin.

\section{United States Drug Induced Liver Injury Network}

DILIN http://dilin.dcri.duke.edu/ Drugs studied: isoniazid, phenytoin and clavulinic acid/amoxicillin.

European collaboration for studying the genetic basis of adverse drug reactions

\section{EUDRAGENE}

(Europe). www.eudragene.org Drugs studied: cholesterol-lowering drugs, thyroid drugs, sulphasalazine, clozapine, antipsychotics, fluoroquinolone, antibiotics and anti-arrythmic agents.

\section{International Warfarin Consortium}

IWPC. http://www.pharmgkb.org/views/project.jsp?pId=56 Drug studied: warfarin. Supported by the US National Institutes of Health (NIH) Pharmacogenetics Research Network and the Pharmacogenetics and Pharmacogenomics Knowledgebase (PharmGKB).

Serious Adverse Event Consortium 


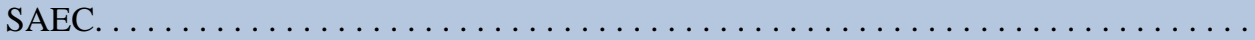
$\ldots \ldots \ldots \ldots \ldots \ldots \ldots \ldots \ldots$ no website available Drugs studied: drugs that are associated with Stevens-Johnson syndrome and drug-induced liver toxicity.

\section{Acknowledgements}

We would like to acknowledge support from the National Institutes of Health (NIH) Pharmacogenetics Research Network: GM61390, U01 HL65962, U01 GM061373, HL 69757, U01 GM074492, U01 DK065201 and K24RR02815 and TR2GM008425 as well as the PhRMA Predoctoral Fellowship. Much of the variant data cited in this article have been deposited in www.pharmgkb.org.

\section{References}

1. Pirmohamed M, Park BK. Genetic susceptibility to adverse drug reactions. Trends Pharmacol. Sci 2001;22:298-305. [PubMed: 11395158]Review of adverse drug reaction (ADR) classifications and more common ADRs (in receptors, enzymes, transporters and immune response genes) with associations to genetic susceptibility.

2. Lazarou J, Pomeranz BH, Corey PN. Incidence of adverse drug reactions in hospitalized patients: a meta-analysis of prospective studies. JAMA 1998;279:1200-1205. [PubMed: 9555760]Frequently cited meta-analysis of 39 prospective studies from US hospitals that determines the incidence of adverse drug reactions in US hospitals.

3. Severino G, Del Zompo M. Adverse drug reactions: role of pharmacogenomics. Pharmacol. Res 2004;49:363-373. [PubMed: 15202516]

4. Pasanen MK, Neuvonen M, Neuvonen PJ, Niemi M. SLCO1B1 polymorphism markedly affects the pharmacokinetics of simvastatin acid. Pharmacogenet. Gen 2006;16:873-879.

5. Giacomini KM, et al. When good drugs go bad. Nature 2007;446:975-977. [PubMed: 17460642]An article highlighting the need for a global research consortium to study mechanisms and risk factors that contribute to severe adverse drug reactions.

6. Molokhia M, McKeigue P. EUDRAGENE: European collaboration to establish a case-control DNA collection for studying the genetic basis of adverse drug reactions. Pharmacogenomics 2006;7:633638. [PubMed: 16753010]

7. Weatherall DJ. Single gene disorders or complex traits: lessons from the thalassaemias and other monogenic diseases. BMJ 2000;321:1117-1120. [PubMed: 11061733]

8. Beutler E. Glucose-6-phosphate dehydrogenase deficiency. N. Engl. J. Med 1991;324:169-174. [PubMed: 1984194]

9. Barta C, et al. Analysis of mutations in the plasma cholinesterase gene of patients with a history of prolonged neuromuscular block during anesthesia. Mol. Genet. Metab 2001;74:484-488. [PubMed: 11749053]

10. Lennard L, Lilleyman JS, Van Loon J, Weinshilboum RM. Genetic variation in response to 6mercaptopurine for childhood acute lymphoblastic leukaemia. Lancet 1990;336:225-229. [PubMed: 1973780]

11. Center for Drug Evaluation and Research. Improving publich health through human drugs. FDA (online). 2005

12. Tufts Center for the Study of Drug Development. Drug safety withdrawals in the US not linked to speed of FDA approval. Tufts University (online). 2005

13. Committee on the assessment of the US drug safety. The Future of Drug Safety: Promoting and Protecting the Health of the Public. The National Academies Press; Washington DC: 2006.

14. Hennessy S, Strom BL. PDUFA reauthorization — drug safety's golden moment of opportunity? N. Engl. J. Med 2007;356:1703-1704. [PubMed: 17435082]

15. DiMasi JA, Hansen RW, Grabowski HG. The price of innovation: new estimates of drug development costs. J. Health Econ 2003;22:151-185. [PubMed: 12606142]

16. Phillips KA, Veenstra DL, Oren E, Lee JK, Sadee W. Potential role of pharmacogenomics in reducing adverse drug reactions: a systematic review. JAMA 2001;286:2270-2279. [PubMed: 11710893]A 
comprehensive, systematic review of the literature on 27 frequently cited drugs in ADRs and the role of potential role of pharmacogenomics in reducing ADRs.

17. Hetherington $S$, et al. Genetic variations in HLA-B region and hypersensitivity reactions to abacavir. Lancet 2002;359:1121-1122. [PubMed: 11943262]

18. Chung WH, et al. Medical genetics: a marker for Stevens-Johnson syndrome. Nature 2004;428:486. [PubMed: 15057820]

19. Watkins PB. Idiosyncratic liver injury: challenges and approaches. Toxicol. Pathol 2005;33:1-5. [PubMed: 15805049]A paper that outlines the clinical presentation of drug-induced liver injury with a special focus on severe drug-induced liver injury (DILI). To fully understand DILI, the author highlights the need for pharmacogenetic studies as well as focused and well-controlled phenotype/ genotype studies of patients who have survived this type of injury.

20. Meier Y, et al. Incidence of drug-induced liver injury in medical inpatients. Eur. J. Clin. Pharmacol 2005;61:135-143. [PubMed: 15726344]

21. Ostapowicz G, et al. Results of a prospective study of acute liver failure at 17 tertiary care centers in the United States. Ann. Intern. Med 2002;137:947-954. [PubMed: 12484709]

22. Bissell DM, Gores GJ, Laskin DL, Hoofnagle JH. Drug-induced liver injury: mechanisms and test systems. Hepatology 2001;33:1009-1013. [PubMed: 11283870]

23. Maddrey WC. Drug-induced hepatotoxicity: 2005. J. Clin. Gastroenterol 2005;39:S83-S89. [PubMed: 15758665]

24. Watkins PB, Whitcomb RW. Hepatic dysfunction associated with troglitazone. N. Engl. J. Med 1998;338:916-917. [PubMed: 9518284]

25. Zimmerman, HJ. Hepatotoxicity the Adverse Effects of Drugs and Other Chemicals on the Liver. Lippincott Williams \& Wilkins; Baltimore: 1999.

26. Kaplowitz N. Idiosyncratic drug hepatotoxicity. Nature Rev. Drug Discov 2005;4:489-499. [PubMed: 15931258]Examines the current understanding of the pathophysiology of idiosyncratic drug hepatotoxicity, outlines its clinical signatures and the role of monitoring in prevention.

27. Hoofnagle JH. Drug-induced liver injury network (DILIN). Hepatology 2004;40:773. [PubMed: 15382161]A description of the drug-induced liver injury network as a network to advance understanding of drug-induced liver disease.

28. Lucena MI, Camargo R, Andrade RJ, Perez-Sanchez CJ, Sanchez De La Cuesta F. Comparison of two clinical scales for causality assessment in hepatotoxicity. Hepatology 2001;33:123-130. [PubMed: 11124828]

29. Randomised trial of cholesterol lowering in 4444 patients with coronary heart disease: the Scandinavian Simvastatin Survival Study (4S). Lancet 1994;344:1383-1389. [PubMed: 7968073]

30. Shepherd J, et al. Prevention of coronary heart disease with pravastatin in men with hypercholesterolemia. West of Scotland coronary prevention study group. N. Engl. J. Med 1995;333:1301-1307. [PubMed: 7566020]

31. Yee HS, Fong NT. Atorvastatin in the treatment of primary hypercholesterolemia and mixed dyslipidemias. Ann. Pharmacother 1998;32:1030-1043. [PubMed: 9793596]

32. Thompson PD, Clarkson P, Karas RH. Statin-associated myopathy. JAMA 2003;289:1681-1690. [PubMed: 12672737]

33. McKenney JM, Davidson MH, Jacobson TA, Guyton JR. Final conclusions and recommendations of the National Lipid Association Statin Safety Assessment Task Force. Am. J. Cardiol 2006;97:8994.This article summarizes the final conclusions of the national lipid association (NLA) statin safety task force, based on a review and independent research of new drug application information, FDA adverse event reporting system (AERS) data, cohort and clinical trial results, analysis of administrative claims database information and the assessment of its four expert panels, which focused on issues of statin safety with regard to liver, muscle, renal and neurologic systems.

34. McClure DL, Valuck RJ, Glanz M, Murphy JR, Hokanson JE. Statin and statin-fibrate use was significantly associated with increased myositis risk in a managed care population. J. Clin. Epidemiol 2007;60:812-818. [PubMed: 17606177]

35. Thompson PD, Clarkson PM, Rosenson RS. An assessment of statin safety by muscle experts. Am. J. Cardiol 2006;97:69-76. 
36. Phillips PS, et al. Statin-associated myopathy with normal creatine kinase levels. Ann. Intern. Med 2002;137:581-585. [PubMed: 12353945]

37. Pasternak RC, et al. ACC/AHA/NHLBI clinical advisory on the use and safety of statins. Circulation 2002;106:1024-1028. [PubMed: 12186811]

38. Chan J, Hui RL, Levin E. Differential association between statin exposure and elevated levels of creatine kinase. Ann. Pharmacother 2005;39:1611-1616. [PubMed: 16160000]

39. Wilke RA, Moore JH, Burmester JK. Relative impact of CYP3A genotype and concomitant medication on the severity of atorvastatin-induced muscle damage. Pharmacogenet. Gen $2005 ; 15: 415-421$.Association study using a retrospective cohort to determine whether there is an association of genetic variants of CYP3A with atorvastatin-induced muscle-damage.

40. Draeger A, et al. Statin therapy induces ultrastructural damage in skeletal muscle in patients without myalgia. J. Pathol 2006;210:94-102. [PubMed: 16799920]

41. Graham DJ, et al. Incidence of hospitalized rhabdomyolysis in patients treated with lipid-lowering drugs. JAMA 2004;292:2585-2590. [PubMed: 15572716]

42. Davidson MH. Rosuvastatin safety: lessons from the FDA review and post-approval surveillance. Expert Opin. Drug Saf 2004;3:547-557. [PubMed: 15500414]

43. Ferdinand KC. Rosuvastatin: a risk-benefit assessment for intensive lipid lowering. Expert Opin. Pharmacother 2005;6:1897-1910. [PubMed: 16144509]

44. Lennernas H. Clinical pharmacokinetics of atorvastatin. Clin. Pharmacokinet 2003;42:1141-1160. [PubMed: 14531725]

45. Gibson DM, et al. Effect of age and gender on pharmacokinetics of atorvastatin in humans. J. Clin. Pharmacol 1996;36:242-246. [PubMed: 8690818]

46. Worz CR, Bottorff M. The role of cytochrome P450-mediated drug-drug interactions in determining the safety of statins. Expert Opin. Pharmacother 2001;2:1119-1127. [PubMed: 11583063]

47. Neuvonen PJ, Kantola T, Kivisto KT. Simvastatin but not pravastatin is very susceptible to interaction with the CYP3A4 inhibitor itraconazole. Clin. Pharmacol. Ther 1998;63:332-341. [PubMed: 9542477]

48. Bullen WW, Miller RA, Hayes RN. Development and validation of a high-performance liquid chromatography tandem mass spectrometry assay for atorvastatin, ortho-hydroxy atorvastatin, and para-hydroxy atorvastatin in human, dog, and rat plasma. J. Am. Soc. Mass Spectrom 1999;10:5566. [PubMed: 9888185]

49. Nordin C, Dahl ML, Eriksson M, Sjoberg S. Is the cholesterol-lowering effect of simvastatin influenced by CYP2D6 polymorphism? Lancet 1997;350:29-30. [PubMed: 9217719]

50. Mulder AB, et al. Association of polymorphism in the cytochrome CYP2D6 and the efficacy and tolerability of simvastatin. Clin. Pharmacol. Ther 2001;70:546-551. [PubMed: 11753271]

51. Geisel J, Kivisto KT, Griese EU, Eichelbaum M. The efficacy of simvastatin is not influenced by CYP2D6 polymorphism. Clin. Pharmacol. Ther 2002;72:595-596. [PubMed: 12426523]

52. Mulder AB, van den Bergh FA, Vermes I. Response to "The efficacy of simvastatin is not influenced by CYP2D6 polymorphism” by Geisel et al. Clin. Pharmacol. Ther 2003;73:475. [PubMed: 12732847]

53. Prueksaritanont T, Ma B, Yu N. The human hepatic metabolism of simvastatin hydroxy acid is mediated primarily by CYP3A, and not CYP2D6. Br. J. Clin. Pharmacol 2003;56:120-124. [PubMed: 12848784]

54. Kirchheiner J, et al. Influence of CYP2C9 polymorphisms on the pharmacokinetics and cholesterollowering activity of (-)-3S, 5R-fluvastatin and (+)-3R, 5S-fluvastatin in healthy volunteers. Clin. Pharmacol. Ther 2003;74:186-194. [PubMed: 12891229]

55. Kirchheiner J, Roots I, Goldammer M, Rosenkranz B, Brockmoller J. Effect of genetic polymorphisms in cytochrome p450 (CYP) 2C9 and CYP2C8 on the pharmacokinetics of oral antidiabetic drugs: clinical relevance. Clin. Pharmacokinet 2005;44:1209-1225. [PubMed: 16372821]

56. Mauro VF. Clinical pharmacokinetics and practical applications of simvastatin. Clin. Pharmacokinet 1993;24:195-202. [PubMed: 8343198]

57. Prueksaritanont T, et al. Effects of fibrates on metabolism of statins in human hepatocytes. Drug Metab. Dispos 2002;30:1280-1287. [PubMed: 12386136] 
58. Jemal M, Ouyang Z, Chen BC, Teitz D. Quantitation of the acid and lactone forms of atorvastatin and its biotransformation products in human serum by high-performance liquid chromatography with electrospray tandem mass spectrometry. Rapid Commun. Mass Spectrom 1999;13:1003-1015. [PubMed: 10368976]

59. Prueksaritanont T, et al. Mechanistic studies on metabolic interactions between gemfibrozil and statins. J. Pharmacol. Exp. Ther 2002;301:1042-1051. [PubMed: 12023536]

60. Shitara Y, Hirano M, Sato H, Sugiyama Y. Gemfibrozil and its glucuronide inhibit the organic anion transporting polypeptide 2 (OATP2/OATP1B1: SLC21A6)-mediated hepatic uptake and CYP2C8mediated metabolism of cerivastatin: analysis of the mechanism of the clinically relevant drug-drug interaction between cerivastatin and gemfibrozil. J. Pharmacol. Exp. Ther 2004;311:228-236. [PubMed: 15194707]

61. Schneck DW, et al. The effect of gemfibrozil on the pharmacokinetics of rosuvastatin. Clin. Pharmacol. Ther 2004;75:455-463. [PubMed: 15116058]

62. Nishizato Y, et al. Polymorphisms of OATP-C (SLC21A6) and OAT3 (SLC22A8) genes: consequences for pravastatin pharmacokinetics. Clin. Pharmacol. Ther 2003;73:554-565. [PubMed: 12811365]

63. Mwinyi J, Johne A, Bauer S, Roots I, Gerloff T. Evidence for inverse effects of OATP-C (SLC21A6) 5 and $1 \mathrm{~b}$ haplotypes on pravastatin kinetics. Clin. Pharmacol. Ther 2004;75:415-421. [PubMed: 15116054]

64. Niemi M, Pasanen MK, Neuvonen PJ. SLCO1B1 polymorphism and sex affect the pharmacokinetics of pravastatin but not fluvastatin. Clin. Pharmacol. Ther 2006;80:356-366. [PubMed: 17015053]

65. Wilke RA, Reif DM, Moore JH. Combinatorial pharmacogenetics. Nature Rev. Drug Discovery 2005;4:911-918. A review proposing the application of multifactor dimensionality reduction to defining gene-gene interactions directed toward the characterization of drug-treatment outcomes, especially targeting polymorphic drug-metabolizing enzymes and their role in adverse drug reactions.

66. Ishikawa $\mathrm{C}$, et al. A frameshift variant of CYP2C8 was identified in a patient who suffered from rhabdomyolysis after administration of cerivastatin. J. Hum. Genet 2004;49:582-585. [PubMed: 15365880]

67. Morimoto K, et al. A novel variant allele of OATP-C (SLCO1B1) found in a Japanese patient with pravastatin-induced myopathy. Drug Metab. Pharmacokinet 2004;19:453-455. [PubMed: 15681900]

68. Fiegenbaum M, et al. The role of common variants of ABCB1, CYP3A4, and CYP3A5 genes in lipidlowering efficacy and safety of simvastatin treatment. Clin. Pharmacol. Ther 2005;78:551-558. [PubMed: 16321621]

69. Vladutiu GD, et al. Genetic risk factors associated with lipid-lowering drug-induced myopathies. Muscle Nerve 2006;34:153-162. [PubMed: 16671104]

70. Oh J, Ban MR, Miskie BA, Pollex RL, Hegele RA. Genetic determinants of statin intolerance. Lipids Health Dis 2007;6:7. [PubMed: 17376224]

71. Roden DM, Woosley RL, Primm RK. Incidence and clinical features of the quinidine-associated long QT syndrome: implications for patient care. Am.Heart J 1986;111:1088-1093. [PubMed: 3716982]

72. Soyka LF, Wirtz C, Spangenberg RB. Clinical safety profile of sotalol in patients with arrhythmias. Am.J. Cardiol 1990;65:74-81.

73. Stambler BS, et al. Efficacy and safety of repeated intravenous doses of ibutilide for rapid conversion of atrial flutter or fibrillation. Circulation 1996;94:1613-1621. [PubMed: 8840852]

74. Torp-Pedersen C, et al. Dofetilide in patients with congestive heart failure and left ventricular dysfunction. Danish Investigations of Arrhythmia and Mortality on Dofetilide Study Group. N. Engl. J. Med 1999;341:857-865. [PubMed: 10486417]

75. Torp-Pedersen C, Moller M, Kober L, Camm AJ. Dofetilide for the treatment of atrial fibrillation in patients with congestive heart failure. Eur. Heart J 2000;21:1204-1206. [PubMed: 10924306]

76. Kay GN, Plumb VJ, Arciniegas JG, Henthorn RW, Waldo AL. Torsades de pointes: The long-short initiating sequence and other clinical features: Observations in 32 patients. J. Am. Coll. Cardiol 1983;2:806-817. [PubMed: 6630761]

77. Viskin S, Justo D, Halkin A, Zeltser D. Long QT syndrome caused by noncardiac drugs. Prog. Cardiovasc. Dis 2003;45:415-427. [PubMed: 12704598] 
78. Dangman KH, Hoffman BF. In vivo and in vitro antiarrhythmic and arrhythmogenic effects of $N$ acetyl procainamide. J. Pharmacol. Exp. Ther 1981;217:851-862. [PubMed: 6164783]

79. Strauss HC, Bigger JT, Hoffman BF. Electrophysiological and beta-receptor blocking effects of MJ 1999 on dog and rabbit cardiac tissue. Circ. Res 1970;26:661-678. [PubMed: 4393105]

80. Antzelevitch C, et al. Heterogeneity within the ventricular wall: electrophysiology and pharmacology of epicardial, endocardial, and M cells. Circ. Res 1991;69:1427-1449. [PubMed: 1659499]

81. Davidenko JM, Cohen L, Goodrow R, Antzelevitch C. Quinidine-induced action potential prolongation, early afterdepolarizations, and triggered activity in canine Purkinje fibers. Circulation 1989;79:674-686. [PubMed: 2917391]

82. Roden DM, Hoffman BF. Action potential prolongation and induction of abnormal automaticity by low quinidine concentrations in canine Purkinje fibers. Relationship to potassium and cycle length. Circ. Res 1985;56:857-867. [PubMed: 4006095]

83. Choy AMJ, Darbar D, Dell'Orto S, Roden DM. Increased sensitivity to QT prolonging drug therapy immediately after cardioversion to sinus rhythm. J. Am. Coll. Cardiol 1999;34:396-401. [PubMed: 10440151]

84. Makkar RR, Fromm BS, Steinman RT, Meissner MD, Lehmann MH. Female gender as a risk factor for torsades de pointes associated with cardiovascular drugs. JAMA 1993;270:2590-2597. [PubMed: 8230644]

85. Roden DM. Drug-induced prolongation of the QT Interval. N. Engl. J. Med 2004;350:1013-1022. [PubMed: 14999113]

86. Roden DM. An underrecognized challenge in evaluating postmarketing drug safety. Circulation 2005;111:246-248. [PubMed: 15668350]

87. Roden DM, Viswanathan PC. Genetics of acquired long QT syndrome. J. Clin. Invest 2005;115:20252032. [PubMed: 16075043]

88. Fenichel RR, et al. Drug-induced torsades de pointes and implications for drug development. J. Cardiovasc. Electrophysiol 2004;15:475-495. [PubMed: 15090000]One of several reviews on the implications for drug development and regulation of the link between HERG/IKr channel block and drug-induced torsades de pointes.

89. Haverkamp W, et al. The potential for QT prolongation and proarrhythmia by non-antiarrhythmic drugs: clinical and regulatory implications. Report on a policy conference of the European Society of Cardiology. Eur. Heart J 2000;21:1216-1231. [PubMed: 10924311]

90. Anderson ME, Al Khatib SM, Roden DM, Califf RM. Cardiac repolarization: current knowledge, critical gaps, and new approaches to drug development and patient management. Am. Heart J 2002;144:769-781. [PubMed: 12422144]

91. Jervell A, Lange-Nielsen F. Congenital deaf-mutism, functional heart disease with prolongation of the QT interval and sudden death. Am. Heart J 1957;54:59-68. [PubMed: 13435203]

92. Romano C, Gemme G, Pongiglione R. Aritmie cardiache rare in eta' pediatrica. Clin. Pediatr 1963;45:656-683.

93. Ward OC. A new familial cardiac syndrome in children. J. Irish Med. Assoc 1964;54:103-106.

94. Abbott GW, et al. MiRP1 forms $\mathrm{I}_{\mathrm{Kr}}$ potassium channels with HERG and is associated with cardiac arrhythmia. Cell 1999;97:175-187. [PubMed: 10219239]

95. Curran ME, et al. A molecular basis for cardiac arrhythmia: HERG mutations cause long QT syndrome. Cell 1995;80:795-803. [PubMed: 7889573]

96. Domingo A, et al. Sodium channel $\beta 4$ subunit mutation causes congenital long QT syndrome. Heart Rhythm 2006;5:S34.

97. Mohler PJ, et al. Ankyrin-B mutation causes type 4 long-QT cardiac arrhythmia and sudden cardiac death. Nature 2003;421:634-639. [PubMed: 12571597]

98. Plaster NM, et al. Mutations in Kir2.1 cause the developmental and episodic electrical phenotypes of Andersen's Syndrome. Cell 2001;105:511-5199. [PubMed: 11371347]

99. Splawski I, et al. $\mathrm{Ca}(\mathrm{V}) 1.2$ calcium channel dysfunction causes a multisystem disorder including arrhythmia and autism. Cell 2004;119:19-31. [PubMed: 15454078] 
100. Splawski I, Tristanti-Firouzi M, Lehmann MH, Sanguinetti MC, Keating MT. Mutations in the hminK gene cause long QT syndrome and suppress $\mathrm{I}_{\mathrm{Ks}}$ function. Nature Genet 1997;17:338-340. [PubMed: 9354802]

101. Vatta M, et al. Mutant caveolin-3 induces persistent late sodium current and is associated with longQT syndrome. Circulation 2006;114:2104-2112. [PubMed: 17060380]

102. Wang Q, et al. Positional cloning of a novel potassium channel gene: KVLQT1 mutations cause cardiac arrhythmias. Nature Genet 1996;12:17-23. [PubMed: 8528244]

103. Wang Q, et al. SCN5A mutations associated with an inherited cardiac arrhythmia, long QT syndrome. Cell 1995;80:805-811. [PubMed: 7889574]

104. Domingo A. Sodium channel á4 subunit mutation causes congenital long QT syndrome. Heart Rhythm 2006;3:S34.

105. Roden DM, et al. Multiple mechanisms in the long QT syndrome: current knowledge, gaps and future directions. Circulation 1996;94:1996-2012. [PubMed: 8873679]

106. Sanguinetti MC, Jiang C, Curran ME, Keating MT. A mechanistic link between an inherited and an acquired cardiac arrhythmia: HERG encodes the $\mathrm{I}_{\mathrm{Kr}}$ potassium channel. Cell 1995;81:299-307. [PubMed: 7736582]

107. Belardinelli L, Antzelevitch C, Vos MA. Assessing predictors of drug-induced torsade de pointes. Trends Pharmacol. Sci 2003;24:619-625. [PubMed: 14654302]

108. Opthof T, et al. Dispersion of repolarization in canine ventricle and the electrocardiographic T wave: Tp-e interval does not reflect transmural dispersion. Heart Rhythm 2007;4:341-348. [PubMed: 17341400]

109. Opthof T, Coronel R, Janse MJ, Rosen MR. A wedge is not a heart. Heart Rhythm 2007;4:11161119.

110. Szabo B, Sweidan R, Rajagopalan CB, Lazzara R. Role of $\mathrm{Na}^{+}: \mathrm{Ca}^{2+}$ exchange current in $\mathrm{Cs}^{+}-$ induced early after-depolarizations in Purkinje fibers. J. Cardiovasc. Electrophysiol 1994;5:933944. [PubMed: 7889233]

111. Priori SG, Napolitano C, Schwartz PJ. Low penetrance in the long-QT syndrome: clinical impact. Circulation 1999;99:529-533. [PubMed: 9927399]

112. Donger C, et al. KVLQT1 C-terminal missense mutation causes a forme fruste long-QT syndrome. Circulation 1997;96:2778-2781. [PubMed: 9386136]

113. Napolitano C, et al. Evidence for a cardiac ion channel mutation underlying drug-induced QT prolongation and life-threatening arrhythmias. J. Cardiovasc. Electrophysiol 2000;11:691-696. [PubMed: 10868744]

114. Yang P, et al. Allelic variants in long QT disease genes in patients with drug-associated torsades de pointes. Circulation 2002;105:1943-1948. [PubMed: 11997281]Examines the role of variants in the congenital long QT syndrome disease genes as modulators of the normal QT or of risk for acquired forms of the disease.

115. Sesti F, et al. A common polymorphism associated with antibiotic-induced cardiac arrhythmia. Proc. Natl Acad. Sci 2000;97:10613-10618. [PubMed: 10984545]

116. Mohler PJ, et al. Defining the cellular phenotype of "Ankyrin-B Syndrome" variants: Human ANK2 variants associated with clinical phenotypes display a spectrum of activities in cardiomyocytes. Circulation 2007;115:432-441. [PubMed: 17242276]

117. Wei J, et al. KCNE1 polymorphism confers risk of drug-induced long QT syndrome by altering kinetic properties of IKs potassium channels. Circulation 1999;100:495.

118. Plant LD, et al. A common cardiac sodium channel variant associated with sudden infant death in African Americans, SCN5A S1103Y. J. Clin. Invest 2006;116:430-435. [PubMed: 16453024]

119. Splawski I, et al. Variant of SCN5A sodium channel implicated in risk of cardiac arrhythmia. Science 2002;297:1333-1336. [PubMed: 12193783]

120. Pfeufer A, et al. Common variants in myocardial ion channel genes modify the QT interval in the general population: results from the KORA study. Circ. Res 2005;96:693-701. [PubMed: 15746444]Examines the role of variants in the congenital LQTS disease genes as modulators of the normal QT or of risk for acquired forms of the disease. 
121. Arking DE, et al. A common genetic variant in the NOS1 regulator NOS1AP modulates cardiac repolarization. Nature Genet 2006;38:644-651. [PubMed: 16648850]A paper that uses genomewide association to identify a locus in NOS1AP that modulates normal QT.

122. Woosley RL, Chen Y, Freiman JP, Gillis RA. Mechanism of the cardiotoxic actions of terfenadine. JAMA 1993;269:1532-1536. [PubMed: 8445816]

123. Roden DM. Taking the idio out of idiosyncratic - predicting torsades de pointes. Pacing Clin. Electrophysiol 1998;21:1029-1034. [PubMed: 9604234]

124. Jost N, et al. Restricting excessive cardiac action potential and QT prolongation: a vital role for IKs in human ventricular muscle. Circulation 2005;112:1392-1399. [PubMed: 16129791]

125. Silva J, Rudy Y. Subunit interaction determines IKs participation in cardiac repolarization and repolarization reserve. Circulation 2005;112:1384-1391. [PubMed: 16129795]

126. Lesko LJ, Woodcock J. Translation of pharmacogenomics and pharmacogenetics: a regulatory perspective. Nature Rev. Drug Discov 2004;3:763-769. [PubMed: 15340386]

127. Lesko LJ, et al. Pharmacogenetics and pharmacogenomics in drug development and regulatory decision making: report of the first FDA-PWG-PhRMA-DruSafe Workshop. J. Clin. Pharmacol 2003;43:342-358. [PubMed: 12723455]

128. Campbell G. Some statistical and regulatory issues in the evaluation of genetic and genomic tests. J. Biopharm Stat 2004;14:539-552. [PubMed: 15468751]

129. Genome-wide association study of 14,000 cases of seven common diseases and 3,000 shared controls. Nature 2007;447:661-678. [PubMed: 17554300]

130. Haga SB, Thummel KE, Burke W. Adding pharmacogenetics information to drug labels: lessons learned. Pharmacogenet. Genomics 2006;16:847-854. [PubMed: 17108808]

131. Prometheus, Laboratories Inc.. Imuran (azathioprine), NDA 16-324/S-030 (online). 2005.

132. Questions and answers on new labelling for warfarin (marketed as Coumadin). FDA (online). 2007

133. Pazdur R. Changes in Camptosar package insert regarding dosing recommendations and risk assessment in patients with UGT1A1 enzyme deficiency. FDA (online). 2005

134. Kindmark A, et al. Genome-wide pharmacogenetic investigation of a hepatic adverse event without clinical signs of immunopathology suggests an underlying immune pathogenesis. Pharmacogenomics J 2007;15:15.

135. Acuna G, et al. Pharmacogenetic analysis of adverse drug effect reveals genetic variant for susceptibility to liver toxicity. Pharmacogenomics J 2002;2:327-334. [PubMed: 12439739]

136. Daly AK, et al. Genetic susceptibility to diclofenac-induced hepatotoxicity: contribution of UGT2B7, CYP2C8, and ABCC2 genotypes. Gastroenterology 2007;132:272-281. [PubMed: 17241877]

137. Danoff TM, et al. A Gilbert's syndrome UGT1A1 variant confers susceptibility to tranilast-induced hyperbilirubinemia. Pharmacogenomics J 2004;4:49-53. [PubMed: 14647407]

138. Huang YS, et al. Cytochrome P450 2E1 genotype and the susceptibility to antituberculosis druginduced hepatitis. Hepatology 2003;37:924-930. [PubMed: 12668988]

139. Roy. B, et al. Increased risk of antituberculosis drug-induced hepatotoxicity in individuals with glutathione $S$-transferase M1 'null' mutation. J. Gastroenterol. Hepatol 2001;16:1033-1037. [PubMed: 11595069]

140. Sharma SK, Balamurugan A, Saha PK, Pandey RM, Mehra NK. Evaluation of clinical and immunogenetic risk factors for the development of hepatotoxicity during antituberculosis treatment. Am. J. Respir. Crit. Care Med 2002;166:916-919. [PubMed: 12359646]

141. O'Donohue J, et al. Co-amoxiclav jaundice: clinical and histological features and HLA class II association. Gut 2000;47:717-720. [PubMed: 11034591]

142. Simon T, et al. Combined glutathione-S-transferase M1 and T1 genetic polymorphism and tacrine hepatotoxicity. Clin. Pharmacol. Ther 2000;67:432-437. [PubMed: 10801254]

143. Watanabe I, et al. A study to survey susceptible genetic factors responsible for troglitazoneassociated hepatotoxicity in Japanese patients with type 2 diabetes mellitus. Clin. Pharmacol. Ther 2003;73:435-455. [PubMed: 12732844] 
144. Harrison-Woolrych M, Clark DW, Hill GR, Rees MI, Skinner JR. QT interval prolongation associated with sibutramine treatment. Br. J. Clin. Pharmacol 2006;61:464-469. [PubMed: 16542208]

145. Fitzgerald PT, Ackerman MJ. Drug-induced torsades de pointes: the evolving role of pharmacogenetics. Heart Rhythm 2005;2:S30-S37. [PubMed: 16253929]

146. Paulussen AD, et al. Genetic variations of KCNQ1, KCNH2, SCN5A, KCNE1, and KCNE2 in druginduced long QT syndrome patients. J. Mol. Med 2004;82:182-188. [PubMed: 14760488]

147. Chevalier P, et al. Non-invasive testing of acquired long QT syndrome: evidence for multiple arrhythmogenic substrates. Cardiovasc. Res 2001;50:386-398. [PubMed: 11334843] 


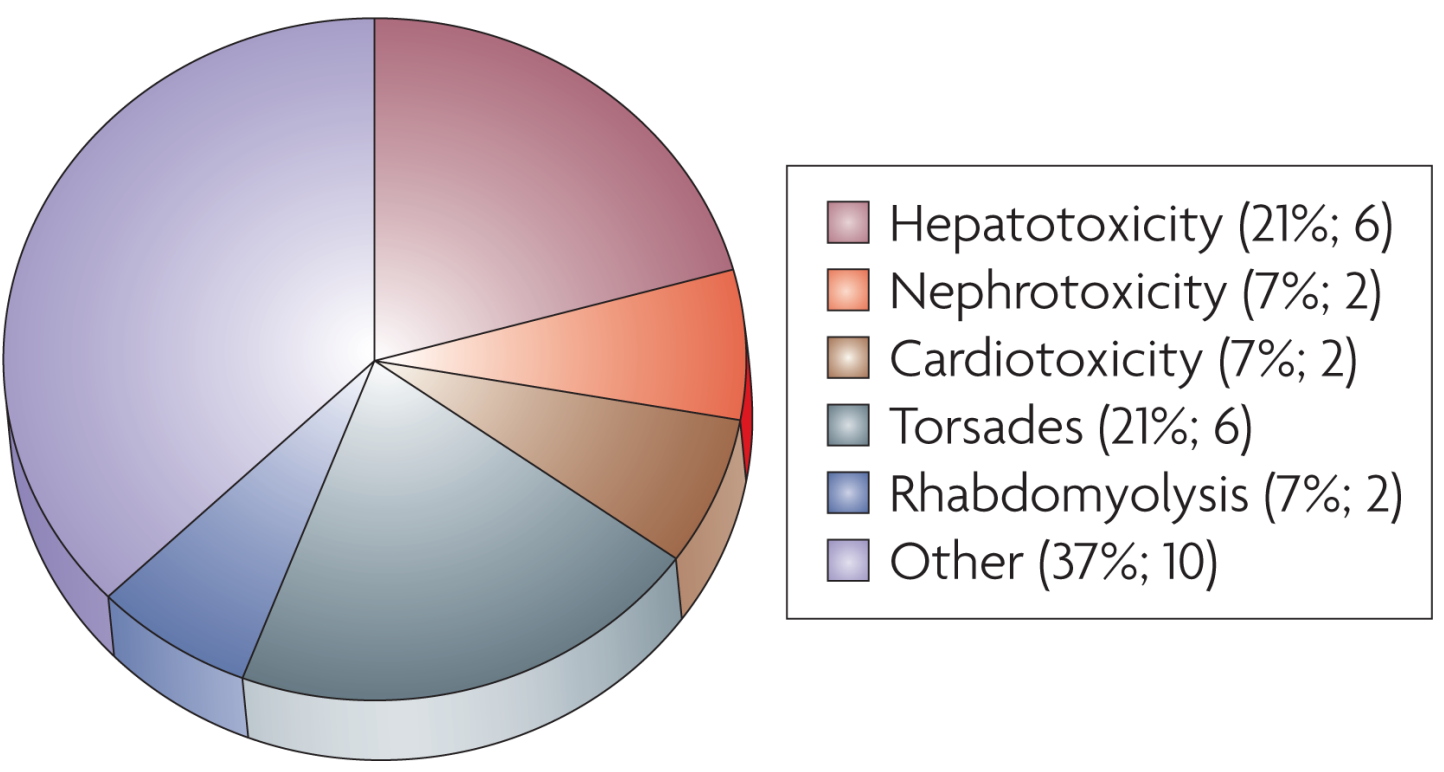

Figure 1. Toxicities leading to drug withdrawal from the US market Drug-induced toxicities associated with 28 drugs that were withdrawn from the US market between 1976 and 2005 (REFS ${ }^{11-13}$ ). Percentage of total and number of cases shown in brackets. Cardiotoxicity refers to heart-related toxicities other than torsades de pointes. 'Other' refers to haemolytic anaemia (1), skin disease (1), immune toxicity (2), gastrointestinal toxicity (1), respiratory toxicity (1), fatal (1), neurotoxicity (1), blood-related toxicity (1) and birth defects (1). 


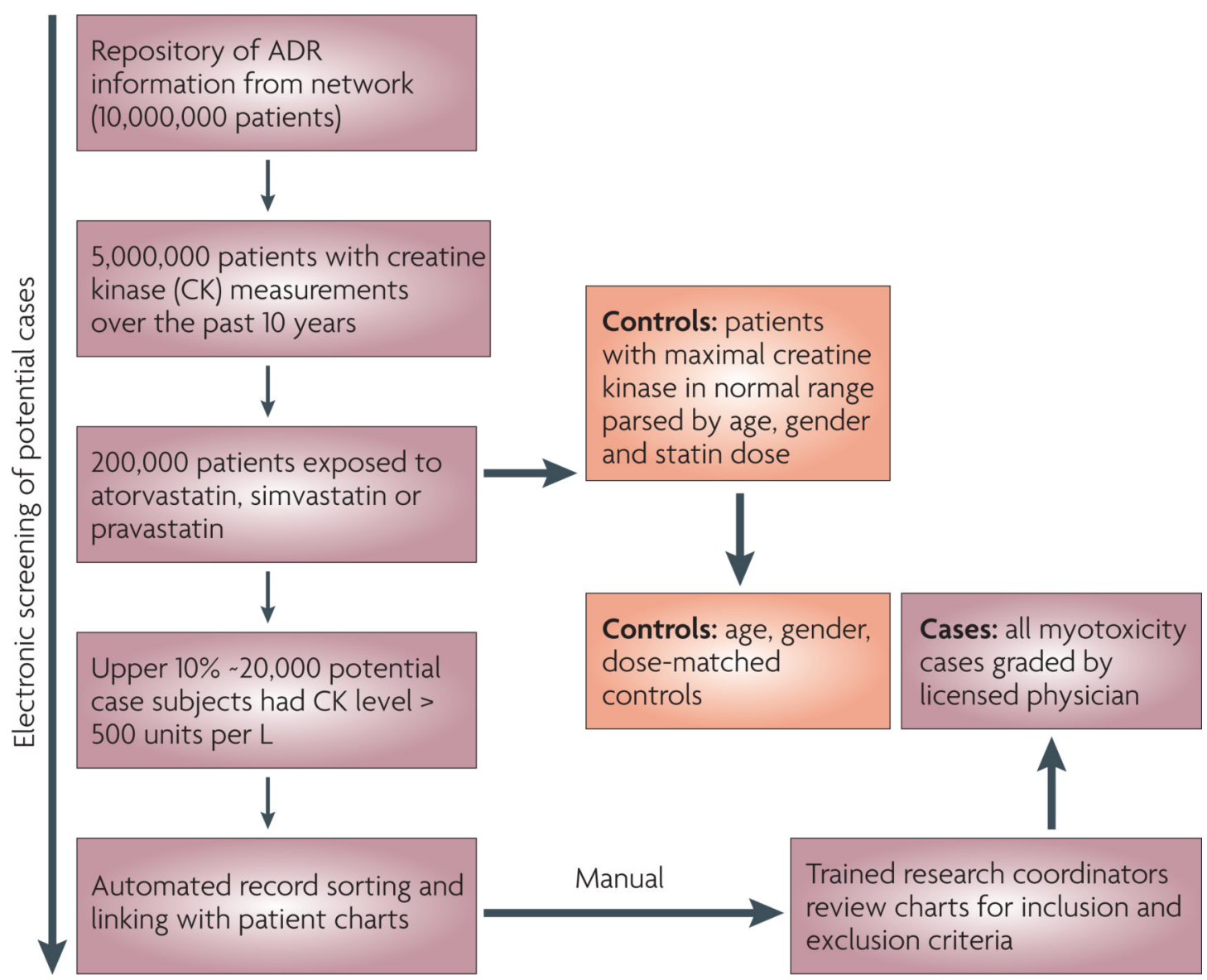

Figure 2. Screening for patients with statin-induced mytotoxicity

In this example of automated case screening a search of an adverse drug reaction (ADR) database resulted in 5,000,000 patients with creatine kinase (CK) measurements and 200,000 of those patients were exposed to statins. These cases included 20,000 patients with elevated CK levels (over 500 units per L), which were linked to their patient charts and were subsequently screened for inclusion/exclusion criteria by trained research coordinators and lastly, by an expert physician. Age and gender matched controls are selected in a similar fashion. This figure was courtesy of R. K. Mareedu (Marshfield Clinic, Wisconsin, USA). 
a

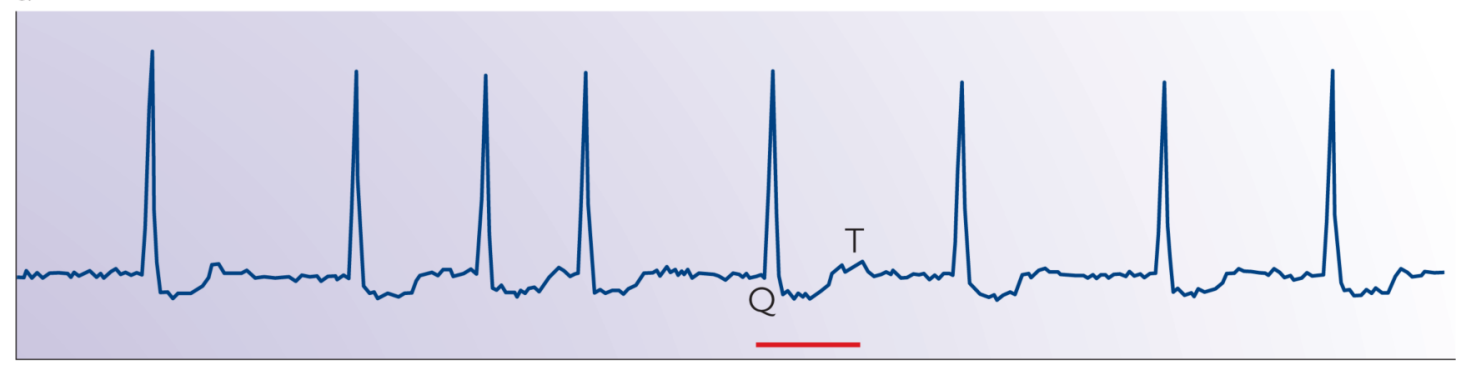

b
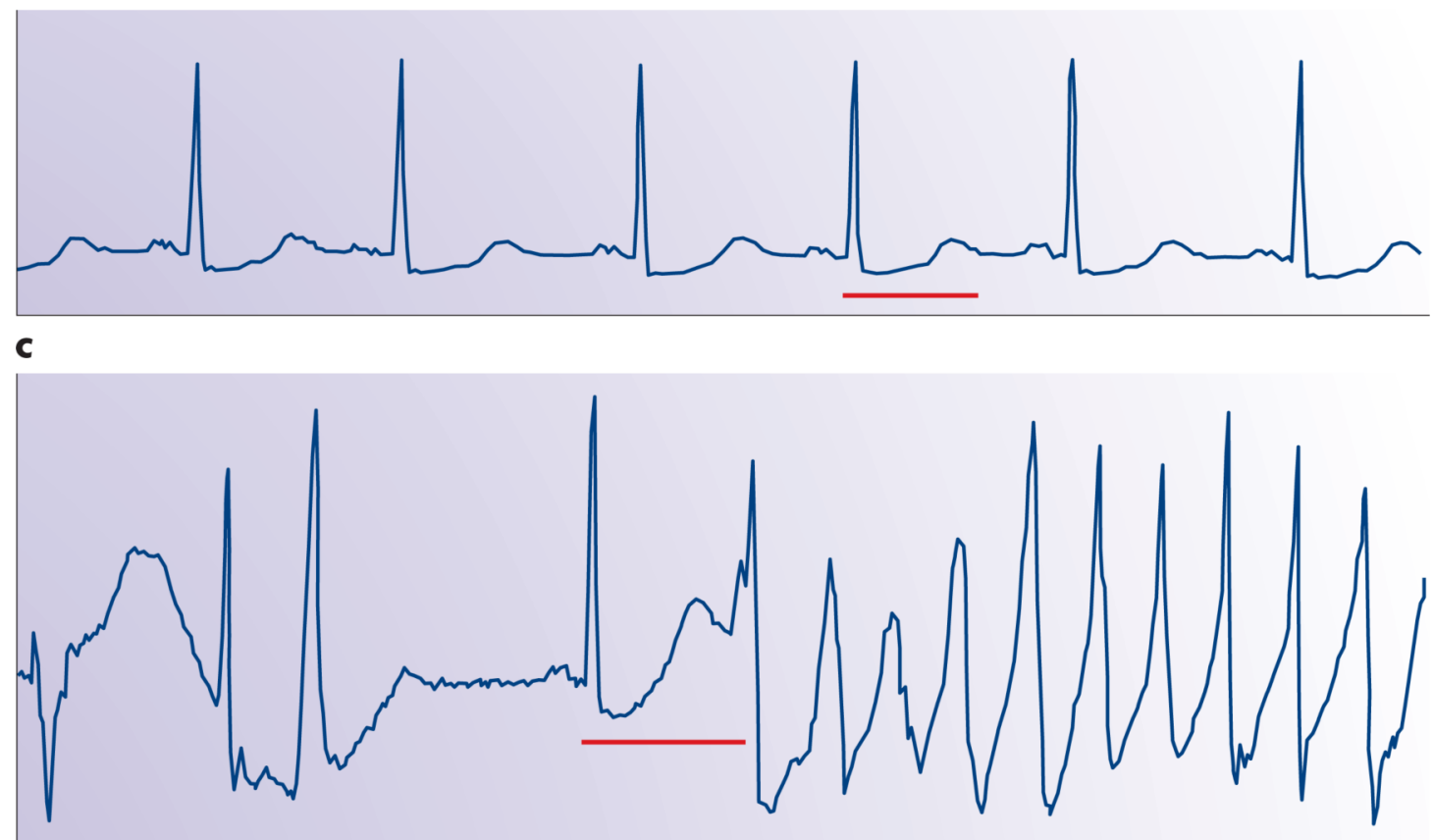

Figure 3. Marked QT interval prolongation and torsades de pointes

An example of QT interval during administration of the anti-arrhythmic drug dofetilide. a $\mid$ QT interval before drug administration, the patient was in atrial fibrillation with a well-controlled ventricular response rate. A QT interval of $420 \mathrm{msec}$ is indicated by the red bar. b | Following a single dose of dofetilide, the rhythm reverted to sinus (the desired therapeutic effect), but the QT interval prolonged markedly, to $560 \mathrm{msec}$. $\mathbf{c}$ Shortly after the patient developed an episode of typical torsades de pointes. The sinus beat just before the arrhythmia displayed a very long QT interval (greater than $640 \mathrm{msec}$ ) and the beat was preceded by a pause. These ECG features are typical of torsades de pointes due to anti-arrhythmic drugs as well as non-cardiovascular medications. 
Wilke et al.

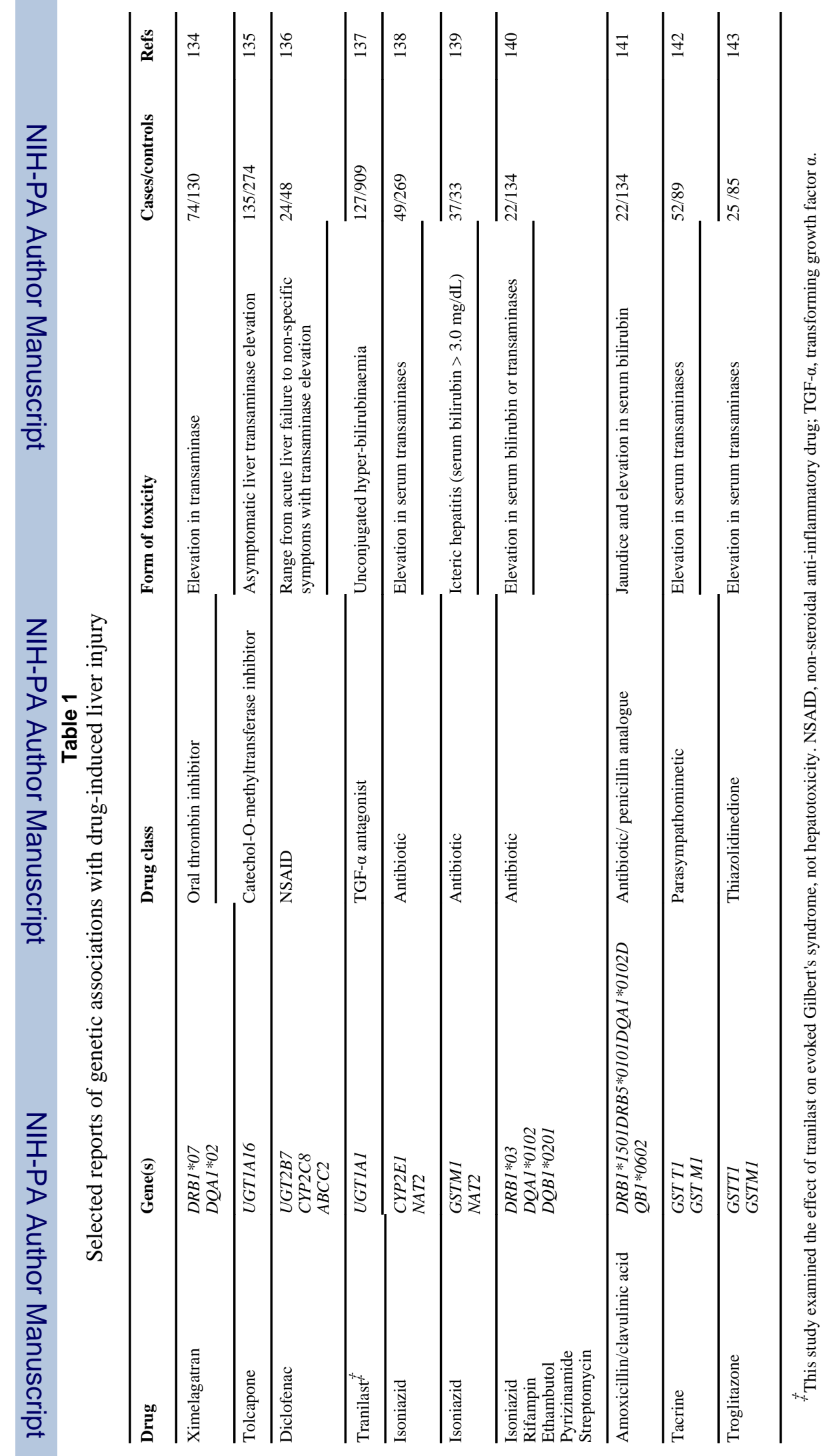

Nat Rev Drug Discov. Author manuscript; available in PMC 2009 October 19. 
Table 2

Genetic variation associated with statin-induced mytotoxicity

\begin{tabular}{|c|c|c|c|c|}
\hline Drug & Gene(s) & Form of toxicity & Cases/controls & Refs \\
\hline Cerivastatin & $\begin{array}{l}\text { CYP2C8 } \\
\text { OATP2 OATP1B1 (SLCO1B1) }\end{array}$ & Rhabdomyolysis & 1 & 66 \\
\hline Pravastatin & $\begin{array}{l}\text { OATPC } \\
\text { OATP1B3 (SLCO1B3) }\end{array}$ & Myopathy & 1 & 67 \\
\hline Simvastatin & $A B C B 1(M D R 1)$ & Myalgia & $15 / 99$ & 68 \\
\hline Atorvastatin & CYP3A5 & Myalgia & $69 / 68$ & 39 \\
\hline $\begin{array}{l}\text { Multiple statins, including } \\
\text { cerivastatin }\end{array}$ & $\begin{array}{c}C P T 2 \\
A M P D \\
-P Y G M\end{array}$ & Myopathy & $136 / 116$ & 69 \\
\hline $\begin{array}{l}\text { Multiple statins, including } \\
\text { rosuvastatin and atorvastatin }\end{array}$ & $C O Q 2$ & Myopathy & $133 / 158$ & 70 \\
\hline
\end{tabular}


Table 3

Associations between polymorphisms and drug-induced torsades de pointes

\begin{tabular}{|c|c|c|c|c|}
\hline Drug & Drug category & Gene(s) & Cases/controls & Refs \\
\hline Sibutramine & Serotonin and noradrenaline re-uptake inhibitor & $K C N Q 1$ & 1 & 144 \\
\hline Terfenadine & $\mathrm{H}_{1}$-receptor antagonist & $H E R G$ & 1 & 145 \\
\hline Multiple, including sotalol and quinidine & Anti-arrhythmics and non-anti-arrhythmics & $\begin{array}{l}\text { KCNQ1 } \\
\text { HERG } \\
\text { SCN5A } \\
\text { KCNQ1 }\end{array}$ & $92 / 67$ & 114 \\
\hline $\begin{array}{l}\text { Cisapride } \\
\text { Bactrim }\end{array}$ & Parasympathomimetic para-aminobenzoic acid inhibitor & $\begin{array}{c}\text { HERG } \\
\text {-SCN5A }\end{array}$ & $32 / 32$ & 146 \\
\hline $\begin{array}{l}\text { Sotalol } \\
\text { Amiodarone } \\
\text { Contrast-media containing iodide }\end{array}$ & $\begin{array}{l}\beta \text {-adrenergic antagonist } \\
\text { Vaughan-Williams class III anti-arrhythmic } \\
\text { Contrast agent }\end{array}$ & $\mathrm{KCNH} 2$ & $9 / 16$ & 147 \\
\hline
\end{tabular}

